\title{
Effectiveness of Second-look Flexible Ureteroscopy to Achieve A True Stone-Free Status in Retrograde Intrarenal Surgery
}

\author{
(D) Oğuz Özden Cebeci , (1) Tayyar Alp Özkan², (1) Mustafa Savaş Yalçın³, (1) Özdal Dillioğlugil4, (1) İbrahim Çevik³ \\ 1 University of Health Sciences Turkiye, Kocaeli Derince Training and Research Hospital, Clinic of Urology, Kocaeli, Turkiye \\ ${ }^{2}$ Acıbadem Kocaeli Hospital, Clinic of Urology, Kocaeli, Turkiye \\ 3 Private Dr. Nazif Bağrıaçık Kadıköy Hospital, Clinic of Urology, İstanbul, Turkiye \\ ${ }^{4}$ Kocaeli University Faculty of Medicine, Department of Urology, Kocaeli, Turkiye
}

\section{What's known on the subject? and What does the study add?}

The most desirable conditions following a successful retrograde intrarenal surgery (RIRS) procedure are a complete flush-out of all stone fragments and no stone-related events yet the residual stone fragments remain a challenging topic for urologists after RIRS. This study is demonstrating the benefits of a second-look flexible ureterorenoscopy (URS) following RIRS. Though in the present study we intervene to single or multiple calyceal stones with a stone basket to achieve a complete stone-free status. Our results confirm that a second-look URS decreases stone-related events for clinically insignificant stones

\begin{abstract}
Objective: Residual stone fragments remain a challenging topic for urologists following retrograde intrarenal surgery (RIRS). This study aimed to investigate the effectiveness of second-look flexible ureteroscopy (URS) to achieve a true stone-free status and decrease stone-related events.

Materials and Methods: The study included 176 consecutive patients treated with RIRS for kidney stones between October 2013 and December 2017. Patients were divided into two groups. Group 1 included patients who underwent only one session of RIRS ( $\mathrm{n}=51$ ) and group 2 included patients who undergo a second-look flexible URS after RIRS $(n=125)$. Both groups were compared for stone-free rates and potential risk factors associated with stone-related events. Stone-related events were defined as urinary infection, renal colic, stone enlargement, and any additional intervention with shock wave lithotripsy or reoperation.

Results: Stone-free rate after RIRS for groups 1 and 2 were $37.25 \%(n=19 / 51)$ and $40.8 \%(n=51 / 125)$, respectively. The stone-free rates improved to 93.6\% ( $n=117 / 125)$ in group 2 after the second-look flexible URS. The multivariable analysis revealed that type of intervention, stone size, and body mass index were independent prognostic factors for stone-related events. When group 2 was taken as a reference, the odds ratio for stone-related events was 8.48 (95\% confidence interval: 2.95-24.42) in group 1.

Conclusion: Second-look flexible ureterorenoscopy increased the stone-free rates and diminished the number of stone-related events. We argue that performing second-look flexible ureterorenoscopy in the early period following RIRS in the presence or suspicion of residual stone fragments provides better treatment results.
\end{abstract}

Keywords: Retrograde intrarenal surgery, second-look flexible ureteroscopy, stone-free rate, residual stone fragments, stone-related event

\section{Introduction}

The most desirable conditions following a successful retrograde intrarenal surgery (RIRS) procedure are a complete flush-out of stone fragments and diminishing stone-related events $(1,2)$. One of the primary metrics used to measure the RIRS outcome is the stone-free rate. Residual stone fragments of $4 \mathrm{~mm}$ or less after RIRS are accepted as clinically insignificant (3). RIRS studies revealed that in almost $20 \%$ of cases, clinically insignificant residual stone fragments are postoperatively observed (4);

Correspondence: Oğuz Özden Cebeci MD, University of Health Sciences Turkiye, Kocaeli Derince Training and Research Hospital, Clinic of Urology, Kocaeli, Turkiye Phone: +90262 3178000 E-mail: oguzozdencebeci@gmail.com ORCID-ID: orcid.org/0000-0003-2444-4661

Received: 05.08.2021 Accepted: 01.09.2021

Cite this article as: Cebeci 0Ö, Özkan TA, Yalçın MS, Dillioğlugil Ö, Çevik İ. Effectiveness of Second-look Flexible Ureteroscopy to Achieve A True Stone-Free Status in Retrograde Intrarenal Surgery. J Urol Surg, 2022;9(1):40-46.

๑Copyright 2022 by the Association of Urological Surgery / Journal of Urological Surgery published by Galenos Publishing House. 
however, these residual stone fragments may grow and cause stone-related events, such as pain and infection $(5,6)$.

Residual stone fragments were detected by ultrasonography (USG), kidneys, ureters, and bladder (KUB) radiography, or computed tomography (CT) (7). The most accurate imaging technique is the CT scan, which may show stones as small as $1 \mathrm{~mm}$, although concerns about radiation exposure limit its use (8). Additionally, CT is underutilized for imaging due to economic reasons; residual stone fragments; therefore, a wide range of stone-free rates are reported following RIRS (9-12).

Various techniques and methods have been reported in the literature to achieve an utterly stone-free status and reduce radiation exposure, including artificial intelligence algorithms $(13,14)$. This study aimed to investigate the effectiveness of second-look flexible ureteroscopy (URS) to achieve a true stone-free status and decrease stone-related events. To our knowledge, the use of routine second-look flexible URS for this purpose has not been previously studied.

\section{Materials and Methods}

This study retrospectively analyzed 282 consecutive patients who were treated with RIRS and laser lithotripsy for kidney stones between October 2013 and December 2017. This study was conducted following the Ethics Committee of Kocaeli Derince Traning and Research Hospital guidelines (approval number: 2018/24). All patients were informed about the procedures and alternative treatment modalities. The surgical choice was made by the patient with counseling from the surgeon. Written informed consent was collected.

A total of 106 patients were excluded as follows: cases in the learning curve $(n=50)$; patients whose RIRS was performed by a different surgeon $(n=29)$; cases with incomplete data on the stone type, CT scan, or follow-up ( $n=18)$; patients with poor visibility secondary to bleeding during RIRS $(n=6)$; and cases of intraoperative complications necessitating secondary procedures $(n=3)$. The remaining 176 patients comprised the study sample.

In this study, the second-look flexible URS procedure refers to the endoscopic control of the renal pelvis and major calyces with a flexible ureteroscope while removing the Double-J stent in the same session.

Patients are divided into two groups based on the type of management. Group 1 included patients undergoing only one session of RIRS $(n=51)$ and group 2 included patients who underwent a second-look flexible URS after RIRS $(n=125)$.

All RIRS operations were performed by a single surgeon (IC) under general anesthesia. A single dose second-generation cephalosporin was used for antibiotic prophylaxis. Before the ureteral access sheet placement, the ureter was examined with a semi-rigid ureteroscope for the presence of ureteral stones and any other unexpected pathology. A ureteral access sheath (9.5 Fr, Flexor Cook) was used. RIRS was performed using a 7.5 Fr Flex X2s (Karl Storz, Germany) URS. A Quantasystem-Litho Holmium: YAG laser (Milan, Italy) with 200-micron fiber was used for stone fragmentation. As possible, all stone fragments were extracted with a $1.7 \mathrm{~F}$ stone basket (NGage ${ }^{\circledR}$ Nitinol stone extractor, Cook, Bloomington, IN, USA). At the end of the RIRS, a 4.7 F Double-J stent was placed in case of ureteral balloon dilatation, first ureteral attempt, prolonged operation time due to stone size, ureteral mucosa edema, suspicious residual stone fragment, or hematuria. Extracted stone fragments were sent for X-ray diffraction stone analysis.

An immediate intraoperative stone-free rate was defined as the absence of stone fragments and reported by the surgeon at the end of the procedure. After RIRS in group 1 and after second-look flexible URS in group 2, X-ray KUB and ultrasound were performed on all patients to determine the presence of residual stone fragments. A detectable stone of any size $(>1$ $\mathrm{mm}$ ) was considered as a residual stone. Unless a complication was observed, patients were discharged on a postoperative day following RIRS.

In cases where a Double-J stent is placed during RIRS, the stent was removed within 2 weeks, and a second-look flexible URS is performed. Residual stone fragments with sizes ranging from 1 $\mathrm{mm}$ to $4 \mathrm{~mm}$ were extracted with a basket catheter during the second-look flexible URS. Laser lithotripsy was applied in two patients with stones larger than $4 \mathrm{~mm}$. A ureteral access sheath was not used while performing a second-look flexible URS, and patients were discharged on the same day of the procedure.

Preoperatively, all patients had routine laboratory work and a CT scan. Unless earlier intervention was indicated, patients received follow-up for stone-related events every 6 months thereafter.

The potential risk factors associated with stone-related events were analyzed, including age, gender, body mass index (BMI), stone size, operative difficulty, CT stone density and size (centralized to the mean and scaled to $5 \mathrm{~mm}$ ), residual stone fragments, stone type, and stone management groups. Stonerelated events were defined as urinary infection, renal colic, stone growth, and any additional shockwave lithotripsy or reoperation. The operative difficulty was categorized, based on the stone location, as accessible (isolated mid or upper calyx or renal pelvis stones), moderate (middle or upper calyx stones, with pelvis stones), or complex (lower calyx stone, with or without pelvis stones). 


\section{Statistical Analysis}

Histograms and the Shapiro-Wilk test were used to test for normally distributed variables. Descriptive analyses were presented using the mean \pm standard deviation. The chi-square test was used to compare categories, and the t-test was used for continuous variables. Univariable and multivariable analyses with logistic regression were used to assess the association between covariates. All analyses were performed using STATA 14.2 (StataCorp, TX). Statistical significance was set at 0.05 , and all tests were two-tailed.

\section{Results}

This study included 176 patients who had initial RIRS for kidney stones. Age, gender, follow-up period, stone side, BMI, and operative difficulty were not significantly different between groups, except for size and density (detailed demographic and clinical data of patients are summarized in Table 1).

Immediate intraoperative stone-free rates for groups 1 and 2 were $43.14 \%(n=22 / 51)$ and $57.6 \%(n=72 / 125)$, respectively. Postoperative radiologically controlled residual stone fragments after the initial RIRS for groups 1 and 2 were $37.25 \%(n=19 / 51)$

\begin{tabular}{|c|c|c|c|}
\hline & $\begin{array}{l}\text { Group } 1 \\
\text { RIRS only } \\
(n=51)\end{array}$ & $\begin{array}{l}\text { Group } 2 \\
\text { Second-look flexible URS } \\
(n=125)\end{array}$ & p-value \\
\hline Age (year); mean \pm SD & $48.8 \pm 15.1$ & $47.9 \pm 11.1$ & 0.68 \\
\hline Follow-up (month); mean \pm SD & $21.2 \pm 10.9$ & $20.5 \pm 11.7$ & 0.69 \\
\hline Female; n (\%) & $18(35.3)$ & $31(24.8)$ & \\
\hline Male; n (\%) & $33(64.7)$ & 94 (75.2) & 0.159 \\
\hline Left side; n (\%) & $25(49)$ & 74 (59.2) & \\
\hline Right side; n (\%) & $26(51)$ & $51(40.8)$ & 0.217 \\
\hline BMI $\left(\mathrm{kg} / \mathrm{m}^{2}\right) ;$ mean $\pm \mathrm{SE}$ & $27.5 \pm 3.7$ & $28.6 \pm 4.2$ & 0.106 \\
\hline Size $(m m) ;$ mean \pm SE & $20.1 \pm 9.3$ & $16.5 \pm 9.1$ & 0.006 \\
\hline \multicolumn{4}{|l|}{ Difficulty; n (\%) } \\
\hline Easy & $31(60.8)$ & $21(16.8)$ & $\mathrm{N} / \mathrm{A}$ \\
\hline Moderate & $7(13.7)$ & 29 (23.2) & $\mathrm{N} / \mathrm{A}$ \\
\hline Hard & $13(25.5)$ & $75(60)$ & $\mathrm{N} / \mathrm{A}$ \\
\hline Stone density (HU); mean \pm SD & $910.8 \pm 320.8$ & $1116.7 \pm 369.8$ & $<0.001$ \\
\hline \multicolumn{4}{|c|}{ Stone composition (Predominant component), n (\%) } \\
\hline Calcium oxalate & $42(82.35)$ & $90(72)$ & N/A \\
\hline Calcium phosphate & $6(11.76)$ & 19 (15.2) & N/A \\
\hline Cystine & $1(1.96)$ & $5(4)$ & N/A \\
\hline Uric acid & $1(1.96)$ & $8(6.4)$ & $\mathrm{N} / \mathrm{A}$ \\
\hline Struvite & $1(1.96)$ & $3(2.4)$ & $\mathrm{N} / \mathrm{A}$ \\
\hline First procedure & \multirow{2}{*}{$19(37.25)$} & \multirow{2}{*}{$51(40.8)$} & \multirow{2}{*}{0.663} \\
\hline Stone-free rate; $\mathbf{n}(\%)$ & & & \\
\hline Second-look URS & \multirow{2}{*}{-} & \multirow{2}{*}{$117(93.6)$} & \multirow{2}{*}{ N/A } \\
\hline Stone-free-rate; $\mathbf{n}(\%)$ & & & \\
\hline \multicolumn{4}{|c|}{ Postoperative stone-related events; n (\%) } \\
\hline No event & $22(43.14)$ & 99 (79.2) & $<0.001$ \\
\hline Asymptomatic stone growth & $2(3.92)$ & $10(8)$ & N/A \\
\hline Urinary infection & $8(15.69)$ & $10(8)$ & $\mathrm{N} / \mathrm{A}$ \\
\hline Renal colic & $3(5.88)$ & $1(0.8)$ & $\mathrm{N} / \mathrm{A}$ \\
\hline Emergency room admission & $1(1.96)$ & - & $\mathrm{N} / \mathrm{A}$ \\
\hline Shock wave lithotripsy & $8(15.69)$ & $1(0.8)$ & $\mathrm{N} / \mathrm{A}$ \\
\hline Reoperation & 7 (13.73) & $4(3.2)$ & $\mathrm{N} / \mathrm{A}$ \\
\hline
\end{tabular}


and $40.8 \%(n=51 / 125)$, respectively. After the second-look flexible URS, stone-free rates improved from $40.8 \%$ to $93.6 \%$ $(n=117 / 125)$; for eight patients who were not considered stonefree, the residual stone fragments that are visibly smaller than $1 \mathrm{~mm}$ were not retrievable with a basket. Four patients (3.2\%) with an initial stone size greater than $2 \mathrm{~cm}$ were reoperated (Table 1).

The univariable analysis indicated that $\mathrm{BMI}$, size, operative difficulty, and type of intervention (group 1 vs. group 2) were significantly associated with SREs (Table 2). The stone-related events rate increased by $19.6 \%$ for each $5 \mathrm{~mm}$ increment in stone sizes. Age, stone density, stone type, side, gender, and radiologic residual stone fragments were not significantly associated with stone-related events (data not shown).

Accordingly, the final model variables included the type of intervention, operative difficulty, stone size, BMI, residual stone, and stone density $(p<0.001)$. The type of intervention, stone size, and BMI were independent prognostic factors for stonerelated events. When group 2 was taken as a reference, the odds ratio was 8.48 [95\% confidence interval (Cl): 2.95-24.42] for stone-related events in group 1. The odds ratio was 1.62 (95\% Cl: 1.21-2.18) for increasing stone size (Table 2).

No postoperative stone-related events were recorded in 69\% $(n=121)$ of the whole cohort. Urinary infection, asymptomatic stone growth, and reoperation were recorded in 10.2\% ( $n=18)$, $6.8 \%(n=12)$, and $6.2 \%(n=11)$ of the patients, respectively.
Postoperative shock wave lithotripsy (SWL) was determined in 9 patients; renal colic in 4, and 1 was admitted to the emergency room due to unrelieved colic symptoms.

Renal colic (5.9\% vs. $1 \%)$, urinary tract infection (16\% vs. $8 \%$ ), emergency room admission (2\% vs. 0), SWL (15.69\% vs. $0.8 \%)$, and reoperation ( $13.8 \%$ vs. $3 \%$ ) rates were significantly higher in group 1, whereas asymptomatic stone growth (4\% vs. $8 \%$ ) was higher in group 2 (Table 1). Initial stone sizes were larger than $20 \mathrm{~mm}$ in patients who had reoperations in group 2 .

\section{Discussion}

Surgical management of kidney stones mainly relies on the stone sizes and locations. Percutaneous nephrolithotomy (PCNL) is the standard procedure for kidney stones larger than $2 \mathrm{~cm}$, and SWL or RIRS is recommended for those smaller than $2 \mathrm{~cm}$ $(1,2)$. However, RIRS obtains a much more common use than is approved in current urology practice $(15,16)$ because "flexible URS is less invasive than PCNL but often with higher stone-free rates than SWL" (17).

The current study performs a second-look flexible URS following the RIRS in patients with a Double-J stent in place, thereby increasing stone-free rates and reducing the probability of stone-related events.

The most desirable conditions following a successful RIRS procedure are a complete flush-out of all stone fragments and

Table 2. Univariable and multivariable regression analyses of stone-related events

\begin{tabular}{|c|c|c|c|c|}
\hline & \multicolumn{2}{|l|}{ Univariable } & \multicolumn{2}{|l|}{ Multivariable } \\
\hline & Odds ratio $(95 \% \mathrm{Cl})$ & p-value & Odds ratio $(95 \% \mathrm{Cl})$ & p-value \\
\hline \multicolumn{5}{|l|}{ Type of intervention } \\
\hline RIRS only & $10.78(4.71-24.65)$ & $<0.001$ & $8.48(2.95-24.42)$ & $<0.001$ \\
\hline \multicolumn{5}{|l|}{ Operative difficulty } \\
\hline Moderate & $0.26(0.09-0.77)$ & 0.016 & $0.67(0.16-2.77)$ & 0.582 \\
\hline Hard & $0.25(0.11-0.58)$ & 0.001 & $0.78(0.24-2.52)$ & 0.68 \\
\hline Stone size, $\mathbf{m m}$ & $1.44(1.19-1.75)$ & $<0.001$ & $1.62(1.21-2.18)$ & 0.001 \\
\hline Body mass index, $\left(\mathrm{kg} / \mathrm{m}^{2}\right)$ & $0.88(0.79-0.98)$ & 0.021 & $0.82(0.72-0.95)$ & 0.006 \\
\hline \multicolumn{5}{|c|}{ Residual stone in radiologic control } \\
\hline$<500$ & 1 Reference & - & 1 Reference & - \\
\hline $500-999$ & $0.48(0.15-1.57)$ & 0.223 & $0.46(0.09-2.31)$ & 0.349 \\
\hline $1000-1500$ & $0.35(0.11-1.15)$ & 0.083 & $0.64(0.13-3.09)$ & 0.576 \\
\hline$>1500$ & $0.13(0.02-0.77)$ & 0.025 & $0.35(0.04-2.95)$ & 0.332 \\
\hline
\end{tabular}


the absence of stone-related events (18). Great treatment results have been reported following RIRS. The CROES study revealed high stone-free rates (85.6\%) and low complication rates (3.5\%) (9). Giusti et al. (10) revealed that stone-free rate values were highest (90.5\%) in small stones at $1 \mathrm{~cm}$ but declined when the stone size increased $(1-2 \mathrm{~cm}, 2-3 \mathrm{~cm}$, and $>3 \mathrm{~cm}$ in diameter with $78.8 \%, 70.5 \%$, and $55 \%$ respectively).

Additionally, studies revealed different stone-free rates when focusing on subgroups. A review of seven RIRS revealed that stone-free rates ranged from $34.8 \%$ to $59.7 \%$, with noncontrast CT performed postoperatively in the first 3 months. Of these patients, 3.7\% to 35\% had to undergo stone surgery again (11). Similarly, Rippel et al. (12) reported a 38\% stone-free rate in patients who underwent $\mathrm{CT}$ control in the postoperative period following RIRS.

The natural history of asymptomatic kidney stones is another controversial issue in the literature. Clinically insignificant kidney stones may not be "insignificant," and residual stone fragments remain a "thorny" issue for both patients and urologists (13). Small and non-occlusive calyceal stones have the potential to both grow and cause pain (19). Stone-related events are observed in more than half of the patients with insignificant stones, the 5-year average SRE observation rate is $51.2 \%$, of whom $14.3 \%$ had to go to the emergency department (20).

Hein et al. (21) have studied influential factors on stone-related events in patients who followed for 5 years after RIRS. They revealed that even smaller than $1-\mathrm{mm}$ residual stone fragments potentially risk the stone-related events following RIRS. They concluded that RIRS should aim for complete stone clearance and that all residual stone fragments should be considered significant regardless of size. The current study improved the stone-free rates and achieved lower stone-related events with a second-look flexible URS. Our stone-related event rate for the whole cohort was $31.25 \%(n=55 / 176)$ at a mean follow-up of 21 months; it was higher in group 1 (56.9\%) than group 2 (20.8\%), a finding that supports the result of Hein et al. (21).

Stone-free status following RIRS is an independent predictor for hospital re-admission and re-hospitalization (3). A study reported that residual stone fragments size of $<4 \mathrm{~mm}$ is prone to grow (28\%), thus almost $20 \%$ of these patients underwent re-intervention. Registered re-intervention rate doubles (38\%) if the size of the fragment is $>4 \mathrm{~mm}$. This study recommended a complete stone-free status to reduce re-intervention following URS (22). Complications associated with flexible URS increased from $7.7 \%$ in the perioperative period to $25.4 \%$ in the first 30 days postoperatively (23).

Our radiologically confirmed residual stone fragments ( $\geq 1 \mathrm{~mm}$ ) after RIRS in group 2 was 59.2\%. Remarkably, this decreased to $6.4 \%$ after the second-look flexible URS procedure $(p<0.001)$
(Table 2). Patients without stone-related events significantly increased from $43.14 \%$ in group 1 to $79.2 \%$ in group 2 (Table 1). We failed to show a significant association with residual stone fragments in the stone-related events in the multivariable analysis; however, we revealed a significant difference between groups 2 and 1 (odds ratio: 8.48) (Table 2). Therefore, secondlook flexible URS is beneficial because it decreases residual stone fragments and stone-related events.

In our clinical practice, stent removal is performed at 2 weeks postoperative. Simultaneous intervention for single or multiple stones that are retractable with a basket during stent removal provides economic and work-related advantages to improve patient satisfaction.

Like previous studies, the current study defines stone-related events to include stone growth, urinary infection, emergency room visit, or additional intervention $(6,24)$. This study revealed that $31.25 \%(n=55 / 176)$ of the whole cohort were observed to have stone-related events at a mean follow-up of 21 months although $6.8 \%(n=12 / 176)$ were asymptomatic.

The radiologically evaluated postoperative stone-free rate after RIRS was $37.25 \%$ and $40.8 \%$ in groups 1 and 2 . This difference was not statistically significant. We report an immediate intraoperative stone-free rate of $57.6 \%(n=72 / 125)$ for group 2 ; however, this proved to be $40.8 \%(n=51 / 125)$. The difference may be due to unfavorable intraoperative conditions, such as bleeding or dusting caused by low visibility. Finally, the stonefree rate increased to $93.6 \%$ after the second-look flexible URS. These residual stone fragments are easy to identify with the absence of dust or bleeding.

Non-contrast CT is recommended for detecting residual stones following RIRS (2), but patients are often at risk of exposure to excessive radiation. The International Commission on Radiological Protection reported thresholds for safe exposure as $50 \mathrm{mSv}$ for a single year or $20 \mathrm{mSv}$ per year for 5 years (25). The 5-year retrospective radiation exposure of patients referred to a tertiary clinic for stone treatment was analyzed. Even based on CT examinations alone, 26\% of these patients were exposed to $>20 \mathrm{mSV}$ per year and $6 \%$ to $>50 \mathrm{mSV}$ per year (26). Patients who applied to the emergency department due to acute stone-related events were exposed to an average of 29.7 $\mathrm{mSv}$ (interquartile range: 24.2-45.1) radiation in their 1-year follow-up. However, 20\% of them were exposed to $>50 \mathrm{mSv}$ annually (27). All patients were radiologically examined with X-ray KUB and USG during the follow-up; CT imaging was not performed of any patient.

Various techniques and methods have been reported in the literature to achieve a completely stone-free status and reduce radiation exposure, including artificial intelligence algorithms. (14). A study aimed to detect residual stone fragments with 
the "Endoluminal Control" method. All calyceal spaces are recontrolled after lithotripsy during RIRS and a 97\% success rate has been reported compared to CT results after 4-8 weeks. They revealed that a $2 \mathrm{~mm}$ residual stone fragment was missed in only one patient. The authors claimed that CT was not required to reduce radiation exposure when residual stone fragments were not seen after endoscopic control (28).

Danilovic et al. (29) revealed that the stone-free rate following RIRS was 93.0\% accurate compared to CT when endoscopically controlled. They revealed no cases of a residual stone fragment of $>2 \mathrm{~mm}$ in CT for patients who were evaluated as stone-free on the endoscopic evaluation.

The term "Second-look Flexible URS" was first used by Breda et al. (30). They used second-look flexible URS as a final diagnostic inspection after a single or repeated RIRS to confirm the stonefree status and revealed that $37 \%(n=19 / 51)$ of the patients had two or more RIRS procedures. Their overall stone-free rates after the first and second RIRS were $64.7 \%$ and $92.2 \%$, respectively. Their stone-free rates for stones of $\leq 2 \mathrm{~cm}$ at first and second RIRS were $79 \%$ and $100 \%$, the stone-free rates for stones of $>2 \mathrm{~cm}$ were $52 \%$ and $85.1 \%$, respectively. They argued that the need for a second-look flexible URS would decrease with experience; however, our results refute this viewpoint because our group 2 had a significant decrease in stone-related event rates (odds ratio: 8.48\%-95\%; $\mathrm{Cl}$ : 2.95-24.42). Therefore, we believe that a routine second-look flexible URS at the time of stent removal may help reduce stone-related events.

Non-randomized, retrospective design is the most important limitation of this study. We excluded data from the first 50 patients in the study to eliminate patients treated during the learning curve; however, we found that patients in group 1 were operated on relatively earlier than patients in group 2, which may be a source of bias in favor of patients in group 2 in terms of surgical expertise.

Evaluation of postoperative stone-free rates without CT suggests that we may have missed small stone fragments. Still, the primary goal of the study was to determine the rate of stone-related events after the second-look flexible URS.

Unfortunately, we were unable to conduct a cost analysis, thus further studies may help quantify the economic implications of using second-look flexible URS.

\section{Conclusion}

Residual stone fragments remain a challenging topic for urologists in stone treatment. We revealed that second-look flexible URS increased the stone-free rates and diminished the number of stone-related events. Additionally, we argue that performing second-look flexible URS in the early period following RIRS in the presence or suspicion of residual stone fragments provides better treatment results.

\section{Ethics}

Ethics Committee Approval: This study was conducted following the Ethics Committee of Kocaeli Derince Traning and Research Hospital guidelines (approval number: 2018/24).

Informed Consent: All patients were informed about the procedures and alternative treatment modalities.

Peer-review: Externally peer-reviewed.

\section{Authorship Contributions}

Surgical and Medical Practices: O.Ö.C., Concept: 0.Ö.C., T.A.Ö., Ö.D., I.Ç., Design: O.Ö.C., T.A.Ö., M.S.Y., Ö.D., I.Ç., Data Collection or Processing: 0.Ö.C., T.A.Ö., M.S.Y., Ö.D., I.Ç., Analysis or Interpretation: 0.Ö.C., T.A.Ö., M.S.Y., Ö.D., I.Ç., Literature Search: 0.Ö.C., T.A.Ö., I.Ç., Writing: 0.Ö.C., T.A.Ö.

Conflict of Interest: No conflict of interest was declared by the authors.

Financial Disclosure: The authors declare that they have no relevant financial.

\section{References}

1. Assimos D, Krambeck A, Miller NL, Monga M, Murad MH, Nelson CP, Pace KT, Pais VM Jr, Pearle MS, Preminger GM, Razvi H, Shah O, Matlaga BR. Surgical Management of Stones: American Urological Association/Endourological Society Guideline, PART I. J Urol 2016;196:1153-1160.

2. Türk C, Petřík A, Sarica $K$, Seitz $C$, Skolarikos $A$, Straub M, Knoll T. EAU Guidelines on Interventional Treatment for Urolithiasis. Eur Urol 2016;69:475-482.

3. Buldu I, Tepeler A, Karatag T, Ozyuvali E, Elbir F, Yordam M, Unsal A. Which factors affect the hospital re-admission and re-hospitalization after flexible ureterorenoscopy for kidney stone? World J Urol 2016;34:1291-1295.

4. Kang $M$, Son $H$, Jeong $H$, Cho MC, Cho SY. Clearance rates of residual stone fragments and dusts after endoscopic lithotripsy procedures using a holmium laser: 2-year follow-up results. World J Urol 2016;34:1591-1597.

5. Candau C, Saussine $C$, Lang $H$, Roy $C$, Faure $F$, Jacqmin D. Natural history of residual renal stone fragments after ESWL. Eur Urol 2000;37:18-22.

6. Rebuck DA, Macejko A, Bhalani V, Ramos P, Nadler RB. The natural history of renal stone fragments following ureteroscopy. Urology 2011;77:564-568.

7. Acar C, Cal C. Impact of Residual Fragments following Endourological Treatments in Renal Stones. Adv Urol 2012;2012:813523.

8. Xiang H, Chan M, Brown V, Huo YR, Chan L, Ridley L. Systematic review and meta-analysis of the diagnostic accuracy of low-dose computed tomography of the kidneys, ureters and bladder for urolithiasis. J Med Imaging Radiat Oncol 2017;61:582-590.

9. de la Rosette J, Denstedt J, Geavlete P, Keeley F, Matsuda T, Pearle M, Preminger G, Traxer 0; CROES URS Study Group. The clinical research office of the endourological society ureteroscopy global study: indications, complications, and outcomes in 11,885 patients. J Endourol 2014;28:131-139.

10. Giusti G, Proietti S, Villa L, Cloutier J, Rosso M, Gadda GM, Doizi S, Suardi N Montorsi F, Gaboardi F, Traxer O. Current Standard Technique for Modern F lexible Ureteroscopy: Tips and Tricks. Eur Urol 2016;70:188-194. 
11. Tokas $T$, Habicher $M$, Junker $D$, Herrmann $T$, Jessen JP, Knoll $T$, Nagele $U$; Training Research in Urological Surgery Technology (T.R.U.S.T.)-Group. Uncovering the real outcomes of active renal stone treatment by utilizing non-contrast computer tomography: a systematic review of the current literature. World J Urol 2017;35:897-905.

12. Rippel CA, Nikkel L, Lin YK, Danawala Z, Olorunnisomo V, Youssef RF, Pearle MS, Lotan Y, Raman JD. Residual fragments following ureteroscopic lithotripsy: incidence and predictors on postoperative computerized tomography. J Urol 2012;188:2246-2251.

13. Prezioso D, Barone B, Di Domenico D, Vitale R. Stone residual fragments: A thorny problem. Urologia 2019;86:169-176.

14. Suarez-Ibarrola $R$, Hein $S$, Miernik A. Residual stone fragments: clinical implications and technological innovations. Curr Opin Urol 2019;29:129134.

15. Chung DY, Kang DH, Cho KS, Jeong WS, Jung HD, Kwon JK, Lee SH, Lee JY. Comparison of stone-free rates following shock wave lithotripsy, percutaneous nephrolithotomy, and retrograde intrarenal surgery for treatment of renal stones: A systematic review and network meta-analysis. PLoS One 2019;14:e211316.

16. Scotland $K B$, Rudnick $B$, Healy KA, Hubosky SG, Bagley DH. Retrograde Ureteroscopic Management of Large Renal Calculi: A Single Institutional Experience and Concise Literature Review. J Endourol 2018;32:603-607.

17. Pearle MS. Is Ureteroscopy as Good as We Think? J Urol 2016;195:823-824.

18. Van Cleynenbreugel B, Kılıç Ö, Akand M. Retrograde intrarenal surgery for renal stones - Part 1. Turk J Urol 2017;43:112-121.

19. Hepsen E, Ozok HU, Cakici MC, Sari S, Karakoyunlu AN, Ersoy H. The effect of renal localization on the fate of clinically insignificant residual fragments after retrograde intrarenal surgery: A prospective 1-year follow-up study. Arch Esp Urol 2021;74:511-518.

20. Li X, Zhu W, Lam W, Yue Y, Duan H, Zeng G. Outcomes of long-term followup of asymptomatic renal stones and prediction of stone-related events. BJU Int 2019;123:485-492.

21. Hein S, Miernik A, Wilhelm K, Schlager D, Schoeb DS, Adams F, Vach W, Schoenthaler M. Endoscopically Determined Stone Clearance Predicts
Disease Recurrence Within 5 Years After Retrograde Intrarenal Surgery. J Endourol 2016;30:644-649.

22. Chew BH, Brotherhood HL, Sur RL, Wang AQ, Knudsen BE, Yong C, Marien T, Miller NL, Krambeck AE, Charchenko C, Humphreys MR. Natural History, Complications and Re-Intervention Rates of Asymptomatic Residual Stone Fragments after Ureteroscopy: a Report from the EDGE Research Consortium. J Urol 2016;195:982-986.

23. Wolff I, May M, Hoschke B, Gilfrich C, Peter J, Ecke T, Schostak M, Lebentrau S. [Differences between the inpatient complication rate after ureterorenoscopy and the 30-day outcome reported by the patient - results of the German prospective BUSTER study]. Aktuelle Urol 2019;50:63-70.

24. Burgher A, Beman M, Holtzman JL, Monga M. Progression of nephrolithiasis: long-term outcomes with observation of asymptomatic calculi. J Endourol 2004; 18:534-539.

25. 1990 Recommendations of the International Commission on Radiological Protection. Ann ICRP 1991;21:1-201.

26. Tzou DT, Zetumer S, Usawachintachit M, Taguchi K, Bechis SK, Duty BD, Harper JD, Hsi RS, Sorensen M, Sur RL, Reliford-Titus S, Chang HC, Isaacson D, Bayne DB, Wang ZJ, Stoller ML, Chi T. Computed Tomography Radiation Exposure Among Referred Kidney Stone Patients: Results from the Registry for Stones of the Kidney and Ureter. J Endourol 2019;33:619-624.

27. Ferrandino MN, Bagrodia A, Pierre SA, Scales CD Jr, Rampersaud E, Pearle MS, Preminger GM. Radiation exposure in the acute and short-term management of urolithiasis at 2 academic centers. J Urol 2009;181:668672.

28. Wilhelm $K$, Hahn 0 , Schoenthaler $M$, Hein $S$, Neubauer J, Schnabel $M$, Neisius A. Stone-Free Rate after Treating Kidney Stones Exceeding $10 \mathrm{~mm}$ via Flexible Ureteroscopy: Can Endoscopic Assessment Replace Low-Dose Computed Tomography Control? Urol Int 2019;103:326-330.

29. Danilovic A, Cavalanti A, Rocha BA, Traxer O, Torricelli FCM, Marchini GS, Mazzucchi E, Srougi M. Assessment of Residual Stone Fragments After Retrograde Intrarenal Surgery. J Endourol 2018;32:1108-1113.

30. Breda A, Ogunyemi O, Leppert JT, Schulam PG. Flexible ureteroscopy and laser lithotripsy for multiple unilateral intrarenal stones. Eur Urol 2009;55:1190-1196. 